Table 1. Studies on SARS-CoV-2 infection pathogenesis

\begin{tabular}{lc}
\hline Research question & $\mathrm{N}$ \\
\hline Cytokines profile & 7 \\
Immune profile & 18 \\
Algorithm & 17 \\
Children & 3 \\
Comorbidities & 1 \\
Endothelial dysfunction and platelets & 8 \\
Gut and microbiota & 3 \\
Genetics and variants & 8 \\
Histology & 7 \\
Antibodies profiles & 8 \\
Viral load and immune response & 4 \\
Interferon & 3 \\
Immunosenecsnce & 3 \\
Total & $90^{*}$ \\
\end{tabular}

*Some manuscripts were including in several research questions. Total number of studies included $\mathrm{n}=85$.

Disclosure of Interests: Aurelie Najm Speakers bureau: BMS, Consultant of: BMS, Alessia Alunno: None declared, Xavier Mariette Speakers bureau: BMS, Eli Lilly, Galapagos, Gilead, GSK, Janssen, Novartis, Pfizer, Servier and UCB, Consultant of: BMS, Eli Lilly, Galapagos, Gilead, GSK, Janssen, Novartis, Pfizer, Servier and UCB, Benjamin Terrier Speakers bureau: Roche, Chugai, Vifor Pharma, GSK, AstraZeneca, Terumo BCT, LFB and Grifols, Consultant of: Roche, Chugai, Vifor Pharma, GSK, AstraZeneca, Terumo BCT, LFB and Grifols, Gabriele De Marco: None declared, Laura Mason: None declared, Jenny Emmel: None declared, Dennis McGonagle Speakers bureau: Abbvie, BMS, Celgene, Eli Lilly, Janssen, MSD, Novartis, Pfizer, Roche and UCB, Consultant of: Abbvie, BMS, Celgene, Eli Lilly, Janssen, MSD, Novartis, Pfizer, Roche and UCB, Pedro M Machado Speakers bureau: Abbvie, BMS, Celgene, Eli Lilly, Janssen, MSD, Novartis, Orphazyme, Pfizer, Roche and UCB, Consultant of: Abbvie, BMS, Celgene, Eli Lilly, Janssen, MSD, Novartis, Orphazyme, Pfizer, Roche and UCB.

DOI: 10.1136/annrheumdis-2021-eular.2851

\section{POS0053 RHEUMATOID ARTHRITIS AND THE RISK OF COVID- 19 DIAGNOSIS, HOSPITALISATION AND DEATH: A POPULATION-BASED MULTI-STATE COHORT ANALYSIS INCLUDING 5,586,565 PEOPLE IN CATALONIA, SPAIN}

A. Vivekanantham ${ }^{1,2}$, E. Burn ${ }^{1,3}$, S. Fernandez-Bertolin3, M. Aragon3, T. Duarte-Salles3, D. Prieto-Alhambra ${ }^{1,4}$. ${ }^{1}$ University of Oxford, Centre for Statistics in Medicine, Nuffield Department of Orthopaedics, Rheumatology, and Musculoskeletal Sciences, Oxford, United Kingdom; ${ }^{2}$ Nuffield Orthopaedic Centre, Rheumatology, Oxford, United Kingdom; ${ }^{3}$ Fundació Institut Universitari per a la recerca a l'Atenció Primària de Salut Jordi Gol i Gurina, (IDIAPJGol), Barcelona, Spain; ${ }^{4}$ Erasmus University Medical Center, Health Data Sciences, Rotterdam, Netherlands

Background: The COVID-19 pandemic caused by the severe acute respiratory syndrome coronavirus 2 (SARS-CoV-2) virus is of particular concern for people with rheumatoid arthritis (RA), with concerns that these people may be at higher risk and have poorer outcomes. However, at present the implications of COVID19 for people with RA remain poorly understood.

Objectives: To investigate the associations between rheumatoid arthritis and the risk of COVID-19 diagnosis, hospitalisation with COVID-19 and COVID-19-related death.

Methods: A population-based cohort study including all individuals registered in the Information System for Research in Primary Care (SIDIAP). SIDIAP includes primary care records covering over $80 \%$ of the population of CataIonia, Spain, and was linked to region-wide SARS-CoV-2 PCR testing, hospital and mortality records. Outpatient diagnoses of COVID-19, hospitalisations with COVID-19 and deaths with COVID-19 were identified as study outcomes between 1st March and 6th May 2020. A multi-state model was used, with cause-specific Cox survival models estimated for each transition, adjusted for age and sex.

Results: A total of 5,586,565 individuals were identified in SIDIAP as of the $1^{\text {st }}$ March 2020, of which 16,344 had RA. RA patients were median (IQR) 63 years $(52.0,74.0)$ and the majority $(n=11,727,71.8 \%)$ were female. Having RA was positively associated with being diagnosed with COVID-19 (adjusted HR 1.14 (1.03 to 1.28)), with hospitalisation with COVID-19 (HR 1.66 (1.35 to 2.04)). However, we did not find an association between RA status and the risk of worsening from outpatient diagnosis to hospitalization or death, or from hospitalization to death (see Table 1).
Table 1. Estimated hazard ratios, adjusted for age and gender, for individuals with rheumatoid arthritis

\begin{tabular}{|c|c|c|c|}
\hline Transition & $\begin{array}{l}\text { Study population } \\
\text { (RA), n }\end{array}$ & $\begin{array}{l}\text { Total events } \\
\text { (RA), } \mathrm{n}\end{array}$ & $\begin{array}{l}\text { Hazard Ratios } \\
\text { (95\% Confidence } \\
\text { Intervals) }\end{array}$ \\
\hline $\begin{array}{l}\text { From general population to diag- } \\
\text { nosed with COVID-19 }\end{array}$ & $5,586,565(16,344)$ & $88,396(324)$ & 1.14 (1.03 to 1.28$)$ \\
\hline $\begin{array}{l}\text { From general population to hospi- } \\
\text { talised with COVID-19 }\end{array}$ & $5,586,565(16,344)$ & $10,143(90)$ & 1.66 (1.35 to 2.04$)$ \\
\hline $\begin{array}{l}\text { From diagnosed with COVID-19 to } \\
\text { hospitalised with COVID-19 }\end{array}$ & $88,396(324)$ & $5,946(30)$ & 0.95 (0.66 to 1.36$)$ \\
\hline $\begin{array}{l}\text { From diagnosed with COVID-19 } \\
\text { to death }\end{array}$ & $88,396(324)$ & 2,295 (16) & 0.96 (0.58 to 1.56$)$ \\
\hline $\begin{array}{l}\text { From hospitalised with COVID-19 } \\
\text { to death }\end{array}$ & $16,089(120)$ & $2,602(27)$ & 1.13 (0.77 to 1.64$)$ \\
\hline
\end{tabular}

Conclusion: To our knowledge, this is the largest study performed to date looking at COVID-19 outcomes in RA patients. Individuals with RA were found to have an increased risk of COVID-19 diagnosis and hospitalisation with COVID-19, compared to the general population. Further research is needed to address factors associated with this including the presence of other co-morbidities, underlying RA disease activity and the use of immunosuppressive medications.

Disclosure of Interests: Arani Vivekanantham: None declared, Edward Burn: None declared, Sergio Fernandez-Bertolin: None declared, Maria Aragon: None declared, Talita Duarte-Salles: None declared, Daniel Prieto-Alhambra Grant/research support from: Dr. Prieto-Alhambra reports grants and other from AMGEN, grants, non-financial support and other from UCB Biopharma, grants from Les Laboratoires Servier, outside the submitted work; and Janssen, on behalf of IMI-funded EHDEN and EMIF consortiums, and Synapse Management Partners have supported train ing programmes organised by DPA's department and open for external participants

DOI: 10.1136/annrheumdis-2021-eular.3160

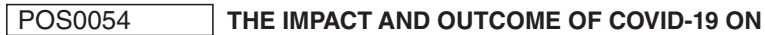 SYSTEMIC SCLEROSIS PATIENTS FROM THE EUROPEAN SCLERODERMA TRIAL AND RESEARCH GROUP (EUSTAR)}

A. M. Hoffmann-Vold ${ }^{1}$, C. Brunborg ${ }^{2}$, F. Tirelli ${ }^{3}$, P. Carreira ${ }^{4}$, N. Del

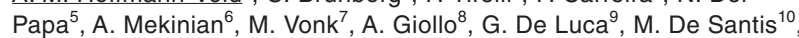
C. Campochiaro ${ }^{9}$, C. Mihai ${ }^{3}$, P. Airò ${ }^{11}$, M. G. Lazzaroni ${ }^{11}$, E. Zanatta ${ }^{12}$, R. Foti ${ }^{13}$, Y. Allanore ${ }^{14}$, D. Furst ${ }^{15}$, M. Matucci-Cerinic ${ }^{16}$, A. Gabrielli ${ }^{17}$, O. Distler ${ }^{3}$. ${ }^{1}$ Oslo University Hospital, Rheumatology, Oslo, Norway; ${ }^{2}$ Oslo University Hospital, Centre for Biostatistics and Epidemiology, Research Support Services, Oslo, Norway; ${ }^{3}$ University Hospital Zurich, University of Zurich, Rheumatology, Zurich, Switzerland; ${ }^{4} 12$ de Octubre University Hospital, Rheumatology, Madrid, Spain; ${ }^{5}$ ASST G. Pini-CTO, University of Milan, Rheumatology, Milan, Italy; ${ }^{6}$ Hôpital Saint Antoine, Internal Medicine, Paris, France; ${ }^{7}$ Radboud University Medical Center, Rheumatology, Nijmegen, Netherlands; ${ }^{8}$ University of Verona, Rheumatology, Verona, Italy; ${ }^{9}$ RCCS San Raffaele Hospital, Vita-Salute San Raffaele University, Immunology, Rheumatology, Allergy and Rare Diseases, Milan, Italy; ${ }^{10}$ IRCCS Humanitas Research Hospital, Rheumatology and Clinical Immunology, Milan, Italy; ${ }^{11}$ ASST Spedali Civili of Brescia, Rheumatology and Clinical Immunology, Brescia, Italy; ${ }^{12}$ University of Padova,

Rheumatology, Padova, Italy; ${ }^{13}$ A.O.U. Policlinico S. Marco, Rheumatology, Catania, Italy; ${ }^{14}$ Cochin Hospital, Université de Paris, Rheumatology, Paris, France; ${ }^{15}$ University of California in Los Angeles, Rheumatology, Los Angeles, United States of America; ${ }^{16}$ University of Florence, Rheumatology, Florence, Italy; ${ }^{17}$ Università Politecnica delle Marche, Scienze Cliniche e Molecolari, Ancona, Italy

Background: Coronavirus disease-19 (COVID-19) has been a major clinica challenge worldwide. Sex, age and comorbidities have been associated with worse outcome in the general population. Systemic sclerosis (SSc) is a severe, autoimmune disease with frequent multi-organ involvement.

Objectives: To assess the impact of COVID-19 and to determine factors associated with worse outcome in SSc patients from the European Scleroderma Trial and Research (EUSTAR) database.

Methods: SSc patients from the EUSTAR database with COVID-19 were prospectively collected between 15.03.-31.12.2020. Two outcomes were chosen: (1) hospitalization; and (2) severe outcome defined as either non-invasive ventilation, mechanical ventilation/extracorporeal membrane oxygenation (ECMO) or death. General risk factors assessed were sex, age and number 
of comorbidities. SSc related risk factors were SSc subtype, autoantibodies, disease duration, SSc associated organ manifestations including interstitial lung disease (ILD), pulmonary arterial hypertension (PAH), cardiac, gastrointestinal (GI), and musculoskeletal involvement; digital ulcers (DU), CRP at last visit, renal disease (scleroderma renal crisis and SSc associated renal insufficiency), modified Rodnan skin score (mRSS) and immunosuppressive treatment. Descriptive statistics and logistic regression models were applied.

Results: In total, 178 European SSc patients with COVID-19 were registered with a median observation time of 5.5 weeks (Table 1). 95 patients $(53 \%)$ could recall SAR-Cov-2 contact, while 47 (26\%) had no contact. 156 (88\%) were symptomatic at COVID-19 onset with fever, cough, malaise and dyspnea being most prevalent. Over the disease course, $63(36 \%)$ developed pneumonia. In total, $67 / 176$ (38\%) were hospitalized which were in $84 \%$ due to COVID-19. 41/170 (24\%) had a severe outcome including $21(12 \%)$ deaths. $128(72 \%)$ recovered completely, while $14(8 \%)$ complained of sequela, with $7(50 \%)$ stating respiratory complications. Age, non-SSc comorbidities, presence of ILD, PAH and SSc associated renal or cardiac disease were numerically associated with hospitalization and severe outcome (Table 1). Univariable logistic analyses for hospitalization and severe outcome are shown in Figure 1. In multivariable logistic regression, age $(\mathrm{OR} 1.03,95 \% \mathrm{Cl}$ 1.01-1.07, $p=0.019$ ), presence of non-SSc comorbidities (OR 2.52, 95\% Cl $1.16-5.47, p=0.019$ ) and SSc-related renal disease (predicting success perfectly) were associated with hospitalization and for severe outcome age (OR $1.05,95 \% \mathrm{Cl} 1.01-1.08)$.

Conclusion: SSc patients at older age, with non-SSc comorbidities, SSc related renal disease or ILD are at risk of a more severe outcome and should follow precautions to avoid COVID-19 infections and need careful monitoring in case of COVID-19.

Table 1. SSc disease characteristics of COVID-19 patients

\begin{tabular}{lccc}
\hline & $\begin{array}{c}\text { All } \\
(\mathrm{n}=172)\end{array}$ & $\begin{array}{c}\text { Hospitalized } \\
(\mathrm{n}=67)\end{array}$ & $\begin{array}{c}\text { Severe outcome } \\
(\mathrm{n}=41)\end{array}$ \\
\hline Age at COVID-19, yrs (SD) & $57(14.0)$ & $63(13.8)$ & $65(12.2)$ \\
Male sex, $\mathrm{n}(\%)$ & $38(21)$ & $18(27)$ & $12(29)$ \\
$\geq 1$ comorbidity, $\mathrm{n}(\%)$ & $63 / 176(36)$ & $37(55)$ & $30(58)$ \\
SSc disease duration at COVID, yrs (SD) & $11.5(8.8)$ & $13.3(9.7)$ & $12.7(10.2)$ \\
Diffuse cutaneous SSc, $\mathrm{n}(\%)$ & $74(42)$ & $29(43)$ & $19(46)$ \\
mRSS, median (IQR) & $5(8)$ & $5(9)$ & $5(7)$ \\
ILD, $\mathrm{n}(\%)$ & $90 / 175(51)$ & $36 / 65(55)$ & $26 / 40(65)$ \\
PAH, $\mathrm{n}(\%)$ & $21 / 175(12)$ & $11 / 65(17)$ & $8 / 40(20)$ \\
Gl disease, $\mathrm{n}(\%)$ & $112 / 176(64)$ & $45(67)$ & $30(73)$ \\
Cardiac disease, $\mathrm{n}(\%)$ & $37 / 166(22)$ & $19 / 59(32)$ & $16 / 36(44)$ \\
Musculoskeletal disease, $\mathrm{n}(\%)$ & $40 / 175(23)$ & $15 / 65(23)$ & $6 / 40(15)$ \\
Renal disease, $\mathrm{n}(\%)$ & $8 / 175(5)$ & $7 / 65(11)$ & $5 / 40(13)$ \\
Ever DU, $\mathrm{n}(\%)$ & $69 / 175(39)$ & $27 / 65(42)$ & $14 / 40(35)$ \\
CRP, nglml (SD) & $35 / 177(20)$ & $14(21)$ & $9(22)$ \\
Immunosuppressive treatment, $\mathrm{n}(\%)$ & $104 / 177(59)$ & $41 / 66(62)$ & $26(63)$ \\
\hline
\end{tabular}
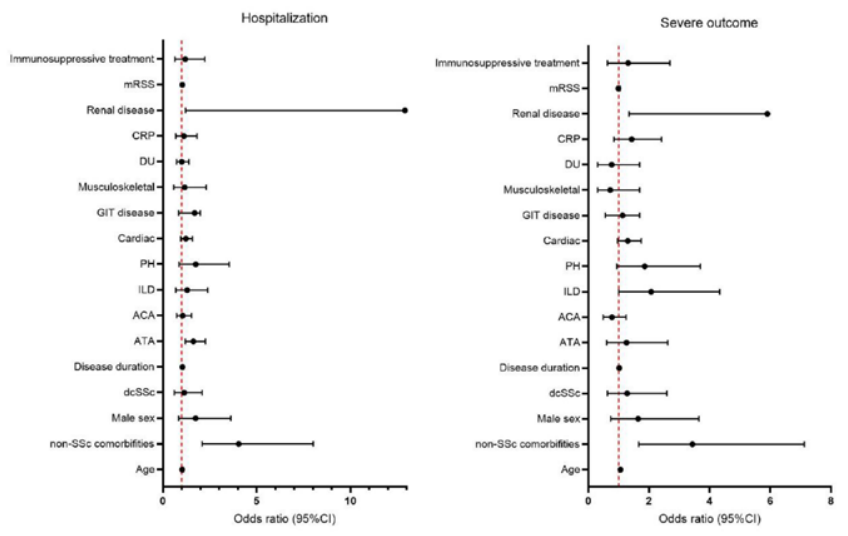

Figure 1. Univariable logistic analyses for hospitalization and severe outcome

Disclosure of Interests: Anna-Maria Hoffmann-Vold Speakers bureau: Actelion, Boehringer Ingelheim, Roche, Merck Sharp \& Dohme, ARXX, Lilly and Medscape, Consultant of: Actelion, Boehringer Ingelheim, Bayer, ARXX, and Medscape
, Grant/research support from: Boehringer Ingelheim, Cathrine Brunborg: None declared, Francesca Tirelli: None declared, Patricia Carreira: None declared, Nicoletta Del Papa: None declared, Arsene Mekinian: None declared, MadeIon Vonk: None declared, Alessandro Giollo: None declared, Giacomo De Luca: None declared, Maria De Santis: None declared, Corrado Campochiaro: None declared, Carina Mihai: None declared, Paolo Airò Speakers bureau: Bristol Myers Squibb, Bohringer Ingelheim, Consultant of: Bristol Myers Squibb, Bohringer Ingelheim, non-financial support from CSL Behring, SOBI, Janssen, Roche, Sanofi, Pfizer, Maria Grazia Lazzaroni: None declared, Elisabetta Zanatta: None declared, Rosario Foti: None declared, Yannick Allanore: None declared, Daniel Furst: None declared, Marco Matucci-Cerinic: None declared, Armando Gabrielli: None declared, Oliver Distler Speakers bureau: Actelion, Kymera Therapeutics, Mitsubishi Tanabe Pharma, Abbvie, Acceleron, Alexion, Amgen, AnaMar, Arxx Therapeutics, Baecon, Discovery, Blade Therapeutics Corbus Pharmaceuticals, Drug Development International, Ltd, CSL Behring, Galapagos NV, Glenmark Pharmaceuticals, GSK, Horizon (Curzion) Pharmaceuticals, Inventiva, iQvia, Kymera Therapeutics, Lilly, Novartis, Pfizer, Topadur and UCB, Consultant of: Actelion, Kymera Therapeutics, Mitsubishi Tanabe Pharma, Abbvie, Acceleron, Alexion, Amgen, AnaMar, Arxx Therapeutics, Baecon, Discovery, Blade Therapeutics, Corbus Pharmaceuticals, Drug Development International, Ltd, CSL Behring, Galapagos NV, Glenmark Pharmaceuticals, GSK, Horizon (Curzion) Pharmaceuticals, Inventiva, iQvia, Kymera Therapeutics, Lilly, Novartis, Pfizer, Topadur and UCB, Grant/research support from: Boehringer Ingelheim.

DOI: 10.1136/annrheumdis-2021-eular.3267

\section{POS0055 SARS-COV-2 OUTBREAK IN AUTOIMMUNE DISEASES: THE EURO-COVIMID STUDY}

D. Saadoun ${ }^{1}$, M. Vieira ${ }^{1}$, M. Vautier ${ }^{1}$, X. Baraliakos ${ }^{2}$, I. Andreica ${ }^{2}$, J. A.

P. Da Silva ${ }^{3}$, M. Sousa ${ }^{3}$, M. Luis $^{3}$, N. Khmelinskii ${ }^{4}$, J. M. Alvaro-Gracia ${ }^{5}$, I. Castrejon ${ }^{5}$, J. C. Nieto González ${ }^{5}$, C. A. Scirè ${ }^{6}$, E. Silvagni ${ }^{6}$, A. Bortoluzzi ${ }^{6}$, H. Penn ${ }^{7}$, S. Hamdulay ${ }^{7}$, P. Machado ${ }^{7}$, B. Fautrel ${ }^{8,9}$, P. Cacoub ${ }^{1}$, M. RescheRigon $^{10}$, L. Gossec ${ }^{8,9} .{ }^{1}$ University Hospitals Pitié Salpêtrière - Charles Foix, Département de Médecine Interne et Immunologie Clinique, Centre National de Références Maladies Autoimmunes systémiques rares, Centre National de Références Maladies Autoinflammatoires et Amylose Inflammatoire, Paris, France; ${ }^{2}$ Ruhr-Universität Bochum, Rheumazentrum Ruhrgebiet, Bochum, Germany; ${ }^{3}$ Centro Hospitalar e Universitário de Coimbra, Rheumatology Department, Coimbra, Portugal; ${ }^{4}$ Hospital de Santa Maria, Rheumatology Department, Lisboa, Portugal: ${ }^{5}$ Gregorio Marañón Hospital, Rheumatology, Madrid, Spain; ${ }^{6}$ University of Ferrara, Department of Medical Sciences, Ferrara, Italy; ${ }^{7}$ Northwick Park Hospital, Department of Rheumatology, London, United Kingdom; ${ }^{8}$ University Hospitals Pitié Salpêtrière - Charles Foix, Rheumatology Department, Paris, France; ${ }^{9}$ Pierre Louis Institute of Epidemiology and Public Health, Inserm UMR 1136, PEPITES team, Paris, France; ${ }^{10}$ Hospital Saint-Louis, URC Saint-Louis, Paris, France

Background: Coronavirus disease 2019 (COVID-19), has raised several questions in patients with immune-mediated inflammatory diseases (IMID). Whether the seroprevalence and factors associated with symptomatic COVID-19 are similar in IMID patients and in the general population is still unknown.

Objectives: To assess the serological and clinical prevalence of COVID-19 in European IMID patients, along with the factors associated with its risk and the impacts the pandemic had on the IMID management.

Methods: Prospective multicentre cross-sectional study among patients with five IMID (i.e. systemic lupus erythematous, Sjögren's syndrome, rheumatoid arthritis, axial spondylarthritis or giant cell arteritis) from six tertiary-referral centers from France, Germany, Italy, Portugal, Spain and United Kingdom. Demographics, comorbidities, IMID, treatments, flares and COVID-19 details were collected. Severe acute respiratory syndrome coronavirus 2 (SARS-CoV-2) serological tests were systematically performed.

Results: Between June 7 and December 8, 2020, 3028 patients were included (median age 58 years, $73.9 \%$ females). SARS-CoV-2 antibodies were detected in 166 (5.5\%) patients. Symptomatic COVID-19 was seen in 122 patients (prevalence: $4.0 \%, 95 \% \mathrm{Cl} 3.4-4.8 \%) ; 23(24.2 \%)$ of them were hospitalized and four (3.2\%) died. In multivariate logistic regression analysis, symptomatic COVID-19 was more likely to be observed in patients with higher levels of $\mathrm{C}$-reactive protein (OR: $1.18 ; 95 \% \mathrm{Cl} 1.05-1.33 ; \mathrm{p}=0.006$ ), and increased with the number of IMID flares (OR: 1.27; $95 \% \mathrm{Cl} 1.02-1.58 ; p=$ $0.03)$. Conversely, it was less likely to occur in patients treated with biological therapy (OR: $0.51 ; 95 \% \mathrm{Cl} 0.32-0.82 ; \mathrm{p}=0.006)$. During the pandemic, at least one self-reported disease flare was seen in $654(21.6 \%)$ patients. Also, 519 $(20.6 \%)$ patients experienced changes in their treatment, with 125 of these (24.1\%) being due to COVID-19. 